\title{
A estimulação da escuta e da compreensão empática na formação interprofissional em saúde
}

\author{
Cláudia Oliveira, Lucia Uchoa-Figueiredo, Nildo Batista, Sylvia Batista
}

\section{Resumo}

A formação profissional em saúde apresenta hoje um modelo mais centrado na doença e menos na história de vida do paciente, repercutindo na despersonalização da relação de cuidar. Embora a necessidade de mudanças no processo de formação venha ganhando força, com a criação de diversos programas de incentivo a essas mudanças, existe ainda uma grande dissonância entre o perfil dos profissionais formados pelas instituições de ensino brasileiras e aquele que se espera para atuação no Sistema Único de Saúde (SUS), é o principal empregador nessa área (ALMEIDA_FILHO,2011). Levando-se em consideração que algumas questões no atendimento em saúde não podem ser objetivadas, existe a necessidade de se apostar em uma formação voltada para a criação de vínculo entre profissional da saúde e paciente, para a empatia, o sentimento de confiança entre ambos e maior adesão do paciente ao tratamento. É nesse contexto que o Campus Baixada Santista da Universidade Federal de São Paulo (UNIFESP-BS) busca romper com o modelo de formação tradicional, centrado nas disciplinas e na formação específica de determinado perfil, a partir de uma proposta pedagógica centrada na formação interprofissional e interdisciplinar em saúde, comprometida com um profissional que esteja apto para o trabalho em equipe (UNIFESP, 2006). Durante a graduação são desenvolvidas metodologias ativas de ensino que orientam os estudantes, desde os anos iniciais da graduação, à articulação entre teoria e prática, à aproximação entre serviços de saúde e ensino, ao trabalho em equipe e à criação de empatia com seus futuros pacientes, entre outros aspectos. Uma dessas metodologias é a produção de narrativas com estudantes do segundo ano dos seis cursos existentes: Educação Física, Fisioterapia, Nutrição, Psicologia, Serviço Social e Terapia Ocupacional. Os estudantes são orientados a construírem narrativas clínicas, em duplas interprofissionais, a partir da escuta da história de vida de moradores de regiões de maior vulnerabilidade social da cidade de Santos/SP. Essa atividade tem sido desenvolvida no Eixo Trabalho em Saúde (TS), no Módulo Prática Clínica Integrada: análise de demandas e necessidades em saúde, com o objetivo de identificar as demandas e necessidades de saúde desses moradores, bem como os recursos e serviços utilizados por eles para cuidar da saúde. A escrita de narrativas resulta de todo um processo de encontros permeados pelas subjetividades de todos os "outros" envolvidos nessa construção (serviços de saúde, colega de dupla, docentes e quaisquer outros que façam parte da atividade). Trata-se de uma atividade que tem como alicerce a habilidade de saber escutar com atenção, combinando a narrativa à contextualização e à personalização diferenciadoras da subjetividade e do posicionamento focal dos narradores, pois apoia-se na ressonância mutissensorial de todos os sentidos, na atitude fenomenológica e da interpretação. Nessa perspectiva, o presente trabalho tem como objetivo expor os efeitos da atividade de escuta na formação interprofissional em saúde, partindo de um recorte da dissertação de mestrado, intitulada "A formação Interprofissional em Saúde e o Processo de Produção de Narrativas: construindo caminhos de aprendizagem" (OLIVEIRA, 2014). O estudo apresenta uma experiência nova com estudantes de saúde, já na fase inicial da vida acadêmica, na qual eles são colocados em contato com a alteridade, em cenários de aprendizagem reais, por meio da articulação entre serviço de saúde e instituição formadora. A experiência mostra que a construção conjunta de narrativas de histórias de vida pode apresentar-se como uma ferramenta metodológica eficaz para a formação, na medida em que desperta o estudante para a importância de se desenvolver a escuta atenta, como elemento fundamental do encontro dialógico entre futuros profissionais e usuários dos serviços de saúde. A pesquisa foi desenvolvida segundo uma 
ISSN 2179-6750

abordagem qualitativa. Foi aplicado um questionário de múltiplas escolhas a 146 estudantes, do 2o. ano de todos os cursos, sendo selecionados, aleatoriamente, 18 alunos para participar de uma entrevista semiestruturada, aplicada em três fases. As entrevistas foram gravadas, tendo autorização dos entrevistados, e transcritas. Os dados coletados foram analisados segundo a técnica de análise de conteúdo, modalidade análise temática (BARDIN, 2011). De modo geral, os estudantes entrevistados evidenciaram que o exercício da escuta atenta despertou neles o reconhecimento da necessidade de afastar-se de qualquer julgamento, avaliação, aprovação, reprovação ou críticas. De acordo com os resultados, a escuta sensível, apoiada na compreensão empática e na integração de todos os sentidos, pode (trans)formar a sensibilidade dos sujeitos envolvidos na interlocução, a partir de uma nova percepção de si e do outro. Quanto mais (re) conhece o outro, mais o futuro profissional passa a (re)conhecer-se em suas próprias fragilidades, com isso, ele se torna mais apto à superação de preconceitos, de paradigmas e das diferenças, além de estar mais bem preparado para a interpretação dos sinais da enfermidade. Os estudantes demonstraram maior preocupação na oferta do cuidado, pois a atividade evocou neles a responsabilização, a compaixão e a empatia pelos moradores. Estar completamente acessível ao que o outro tem a dizer, na formação em saúde, significa compreender o ser humano em um contexto mais amplo, isto é, do ponto de vista da integralidade no cuidado. A atividade de escuta ativa na graduação em saúde revela, portanto, que os estudantes podem estar mais aptos ao desenvolvimento e fortalecimento de vínculo terapêutico com seus pacientes, na medida em que se mostram mais abertos e receptivos para a oferta do cuidado integral, a partir da compreensão de fatores que extrapolam aspectos do adoecimento meramente biológico.

Descritores: Educação interprofissional, Ensino em saúde, Escuta, Narrativa 